\title{
Precocious Puberty in Girls: what Changes in Body Mass Index and Bone Age?
}

\author{
Tatyana S A Silva ${ }^{1}$, Flor de Maria A M Silva ${ }^{2}$, Adriana S Rego ${ }^{3}$ and Eduardo D Figuerêdo ${ }^{4}$ \\ ${ }^{1}$ Masters in Management of Health Programs and Services, Universidade Ceuma São Luis, Brazil \\ ${ }^{2}$ Psychologist, PhD in Public Health, Universidade Ceuma São Luis, Brazil \\ ${ }^{3}$ Physiotherapist, PhD in Public Health, Universidade Ceuma São Luis Brazil \\ ${ }^{4}$ PhD in Public Health Universidade Ceuma São Luis Brazil
}

Submission: May 23, 2020 ; Published: June 05, 2020

*Corresponding author: Eduardo Durans Figuerêdo, Universidade Ceuma, Campus Renascença, Rua Josué Montello, nº 1, Renascença II São Luís, MA, Brazil

\begin{abstract}
Objective: To study Precocious Puberty (PP) and associated factors in girls. Methods: Cross-sectional studies in two specialized health services. The medical records of precocious pubertal girls were collated into study group, and the medical records of non-precocious pubertal girls years were collated into control group. Girls on hormonal treatment or who had disorders of the central nervous system were excluded. Data from the medical records were analyzed using the Student's t-test to determine the association between independent variables and PP. A p-value $<0.05$ was considered statistically significant. Results: A total of 184 girls were studied; 93 girls were considered precocious pubescents, and 91 girls were considered non-precocious pubescents. Girls with PP had a difference of 2.22 years between bone age and chronological age, and those without PP had a difference of 1.26 years ( $\mathrm{p}<0.001)$. Girls with PP had an average bone mass index of $18.05 \mathrm{~kg} / \mathrm{m}^{2}$, and those without PP had an average BMI of $18.86 \mathrm{~kg} / \mathrm{m}^{2}$ ( $\left.\mathrm{p}=0.03\right)$.
\end{abstract}

Keywords: Precocious puberty; Body mass index; Bone age

\section{Introduction}

Puberty is the process of maturation that occurs during adolescence and includes the acquisition of secondary sexual characteristics, rapid bone maturation, and the acceleration of growth. Precocious Puberty (PP) is commonly defined as puberty that starts before the age of 8 years in girls and 9 years in boys [1]. In most cases, PP is due to premature activation of the hypothalamic-pituitary-gonadal axis, which leads to the appearance of secondary sexual characteristics, linear growth acceleration, somatic development, and advanced bone age (BA); advanced BA is due to premature fusion of the growth epiphysis, which compromises a child's height [2]. There are several causes of PP. Those of central origin result from early activation of the hypothalamus-pituitary-ovary axis, which leads to the production of sexual steroids by the ovaries and early pubertal development, with a pattern similar to physiological puberty [3]. Those of peripheral origin result in a production of steroids regardless of axis activation and are not associated with the production of pituitary gonadotropins [3]. The global estimated prevalence of PP is approximately $2 \%$ but varies according to the population, reaching a maximum of $48 \%$ in African American girls [4]. A study of breast development (one of the first signs of female puberty) in the United States of America that involved 1,200 girls aged 6 to 8 years concluded that breast development occurs at an average age of 8 to 9 years but varies according to ethnicity, diet, and other hormonal factors [5]. PP is 10 to 23 times more frequent in girls than boys. A population study in Denmark found that the incidence of PP was 20 cases for every 10,000 girls and 5 cases for every 10,000 boys [6]. In Brazil, a survey conducted between 2000 and 2005 revealed that approximately $50 \%$ of PP cases occur between the age of 6 and 7 years, 25\% of PP cases occur between the age of 2 and 6 years, and 18\% of PP cases occur before the age of 2 years [4]. An understanding of the hormonal changes that accelerate growth speed and early reproductive capacity, and that culminate in the appearance of secondary sexual characteristics is 
fundamental for the doctor; PP is a disease that, when identified early, can be well-managed with effective treatment options. This was the motivation behind our study, and we had the following objective: to study both precocious puberty and its associated factors in girls.

\section{Material and Methods}

We conducted an analytical and cross-sectional study of the medical records of 184 girls aged from 9 to 12 years, who attended either a public or private specialized health service. The girls were divided into two groups: the study group, which consisted of girls with a diagnosis of Precocious Puberty (PP); and the control group, which consisted of girls with no diagnosis of PP. We excluded girls who were undergoing hormonal treatment for another pathology or who had disorders of the central nervous system. Considering a prevalence of PP of $4.5 \%$, a significance level of $5 \%$, and an absolute precision of $3 \%$, we calculated our sample size to be 184 girls. All collected data were stored in MS-Excel ${ }^{\circledR}$ (Microsoft, Charlotte, NC, USA) and then exported to the Stata $13.0 \AA$ program (Statacorp, College Station, TX, USA) for statistical analysis. Quantitative variables were presented as the mean \pm standard deviation, and qualitative variables were presented as the absolute and relative frequencies (percentages). The differences between the means in the two groups were verified using the Student's t-test, and a p-value of $<0.05$ was considered statistically significant. This research project was approved by the Research Ethics Committee of Universidade Ceuma (consubstantiated opinion 2,472,274). Data collection started after the final committee approval and a waiver was issued to the Free and Informed Consent Term because it was a review of medical records. The data collected had no patient identifiers.

\section{Results}

A total of 93 girls with PP and 91 girls without PP were studied ( $n=184$ ). The average age was 10.63 years, the average weight was $46.09 \mathrm{~kg}$, the average height was $1.49 \mathrm{~m}$, and the mean Body Mass Index (BMI) was $18.45 \mathrm{~kg} / \mathrm{m}^{2}$ (underweight). The majority of girls had brown skin (59.78\%) and attended the private health network (88.04\%). Data related to the sociodemographic variables are shown in Table 1. In the 93 girls with PP, onset of symptoms occurred at an average age of 6.4 years, treatment started at an average age of 7.5 years, and the interval between the first symptoms and start of treatment was an average of 1.1 years. When analyzing the difference between BA and chronological age, the girls with PP had a difference of 2.22 years (95\% confidence interval [CI], 1.87-2.56), and those without PP had a difference of 1.26 years $(95 \% \mathrm{CI}, 1.06-1.47)(\mathrm{p}<0.001)$ (Table 2). There was a statistically significant difference in the mean BMI between the two groups. Girls with PP had an average BMI of $18.05 \mathrm{~kg} /$ $\mathrm{m}^{2}\left(17.44-18.65 \mathrm{~kg} / \mathrm{m}^{2}\right)$, and those without PP had an average BMI of $18.86 \mathrm{~kg} / \mathrm{m}^{2}\left(18.21-19.51 \mathrm{~kg} / \mathrm{m}^{2}\right)(\mathrm{p}=0.03)$ (Table 3). The difference in height between girls in the two groups was also analyzed. The girls with PP had an average height of $146.62 \mathrm{~cm}$ (143.52-149.85), and those without PP had an average height of $151.23 \mathrm{~cm}(149.52-153.06)(\mathrm{p}=0.003)$ (Table 4).

Table 1: Sociodemographic variables of girls with and without precocious puberty (2019) $(n=184)$.

\begin{tabular}{|c|c|c|c|}
\hline Variables & Mean \pm Standard deviation & Minimum & Maximum \\
\hline Age (years) & $10.63 \pm 1.61$ & 9 & 12 \\
\hline Weight (kg) & $46.09 \pm 9.40$ & 31 & 76 \\
\hline Height (cm) & $148.89 \pm 10.49$ & 121 & 168 \\
\hline \multirow[t]{2}{*}{$\mathrm{BMI}\left(\mathrm{kg} / \mathrm{m}^{2}\right)$} & $18.45 \pm 3.04$ & 11.24 & 27.87 \\
\hline & $\mathrm{N}$ & $\%$ & \\
\hline \multicolumn{4}{|l|}{ Skin color } \\
\hline White & 55 & 29.89 & \\
\hline Brown & 110 & 59.78 & \\
\hline Black & 19 & 10.33 & \\
\hline \multicolumn{4}{|l|}{ Service category } \\
\hline Public & 22 & 11.96 & \\
\hline Private & 162 & 88.04 & \\
\hline \multicolumn{4}{|l|}{ Precocious Puberty } \\
\hline With precocious puberty & 93 & 50.54 & \\
\hline $\begin{array}{l}\text { Without precocious } \\
\text { puberty }\end{array}$ & 91 & 49.46 & \\
\hline
\end{tabular}




\section{Journal of Gynecology and Women's Health}

Table 2: Difference between bone age and chronological age in girls with and without precocious puberty (2019) $(n=184)$.

\begin{tabular}{|c|c|c|c|c|}
\hline & n & Mean & $\begin{array}{c}\text { Confidence Interval } \\
\text { (95\% CI) }\end{array}$ & P value $^{\mathbf{a}}$ \\
\hline With precocious puberty & 93 & 2.21 & $1.87-2.56$ & $<0.001$ \\
\hline Without precocious puberty & 91 & 1.26 & $1.06-1.47$ & \multirow{2}{*}{} \\
\hline
\end{tabular}

Table 3: Difference between BMI of girls with and without precocious puberty (2019) $(n=184)$.

\begin{tabular}{|c|c|c|c|c|}
\hline & $\mathbf{n}$ & Mean & $\begin{array}{c}\text { Confidence Interval } \\
\text { (95\% CI) }\end{array}$ & P value $^{\mathbf{a}}$ \\
\hline With precocious puberty & 93 & 18.04 & $17.44-18.65$ & 0.03 \\
\hline Without precocious puberty & 91 & 18.86 & $18.21-19.51$ & \multirow{2}{*}{} \\
\hline
\end{tabular}

Table 4: Mean height difference between girls with and without precocious puberty (2019) $(n=184)$.

\begin{tabular}{|c|c|c|c|c|}
\hline & $\mathbf{n}$ & Mean height (cm) & $\begin{array}{c}\text { Confidence Interval } \\
(\mathbf{9 5 \%} \text { CI) }\end{array}$ & P value $^{\mathbf{a}}$ \\
\hline With precocious puberty & 93 & 146.62 & $143.52-149.85$ \\
\hline & & & & 0.003 \\
\hline Without precocious puberty & 91 & 153.23 & $150.52-155.06$ \\
\hline
\end{tabular}

\section{Discussion}

There was a predominance of brown-skinned girls (59.8\%), followed by white-skinned girls (29.9\%) and black-skinned girls (10.3\%). In 2017, the Brazilian Institute of Geography and Statistics [7] revealed that, according to the criteria of declaring color or race, there was a predominance of brown-skinned people in the Brazilian population (76.8\%), followed by whiteskinned people $(18.7 \%)$ and black-skinned people (3.8\%); the data demonstrate that PP has no ethnic relationship. However, some studies, mainly in the United States of America (USA), have shown a predisposition for PP in the African American race [8]. In this study, the average BMI of the girls was $18.05 \mathrm{~kg} / \mathrm{m}^{2}$, which indicates low weight. The study by Carvalho et al. [9] that evaluated cases with suspected PP in relation to classification and etiology showed a BMI of $16.3 \pm 1.8 \mathrm{~kg} / \mathrm{m}^{2}$ in the early-age group. Socioeconomic and nutritional conditions seem to influence the age of onset of puberty [10]. The testing and diagnostic criteria used to classify children as overweight or obese are controversial. $\mathrm{BMI}$ in children and adolescents is related to both age and the stage of sexual maturation. In practice, the measurement of weight and height is used because they are easily obtained during a physical examination.

According to Aksglaede et al. [11], increased adiposity and higher levels of pre-pubertal insulin predict a lower age at menarche. Girls with CPP have increased insulin, adiposity, triglycerides, and low-density lipoproteins, and a decrease in high-density lipoproteins and insulin sensitivity. However, a study by Cruz [12] reported that girls diagnosed with CPP have a worse profile than girls without PP, even though their BMI is generally within the average; this corroborates with the findings of our research. This study found an average difference between chronological age and BA of 2.21 years among early pubertal children and 1.26 years among children without PP $(p<0.001)$. Our results were in agreement with the study by $\mathrm{Xu}, \mathrm{Li}$, and $\mathrm{Li}$ [13] that reported a difference of 2.5 years in a cohort of 237 girls. Benetti-Pinto et al. [14] demonstrated that the average age of treatment initiation for PP was 7.8 years with an average BA of 10.1 years; BA progression was 2.3 years, and it was controlled during the treatment period. An indicator of good health in a child is normal growth. A child's intrauterine growth must be monitored. After birth, height and weight must be measured up to an age of 18 years. Results are placed on growth curves to assess whether a child's growth pattern is comparable with other children of the same sex, age, and family pattern [15]. Adolescents go through a growth spurt that includes an intense phase of growth acceleration followed by a rapid deceleration [16]. In this study, the average height of girls without PP was $4.3 \%$ higher than that girls with PP. This finding is probably due to a growth acceleration and deceleration at an earlier age than expected in the girls with PP.

Sixty-seven percent of the children in this study were from urban areas. Although genetic factors are the main determinants of the onset of puberty, several other factors seem to influence both the age of onset and the progression of pubertal development. The urban population has access to a diet rich in animal fat that results in an increased intake of fatty acids and estrogen producers. In addition, the urban population is exposed to endocrine disruptors found in domestic, industrial, and agricultural chemicals, such as cosmetics, anabolics, medicines, detergents, and soymilk, which can affect hormonal balance. According to Alves et al. [17], even though many of these substances have been banned, they still remain in nature and will remain for a long time because of their 
high stability. Even in small quantities, their ascension through the food chain enhances their biomagnification effect. Approximately $33 \%$ of the children in this study came from the interior of the state. Based on an assumption that the rural community is relatively compromised in terms of knowledge and access to health services, we presumed that the girls with early sexual maturation had a worse quality of life. Families in a rural community that need to care for a child with PP are faced with many difficulties and challenges related to distance and commuting due to the lack of infrastructure and resources from local health services [18]. In regards to the service category, $75.3 \%$ of the children in this study attended the private health network and $23.7 \%$ attended the public health network. Many factors discourage families from seeking care in the public health network: poor accessibility to medical services, low supply of specialized services, and difficulty obtaining laboratory testing [18]. Santos, Ramos, \& Sousa [19] compared the quality of service in public and private health services and demonstrated that quality was not exclusively linked to financial resources, but rather to the health professional performing his or her work with willingness and commitment. The monitoring of a child's development in primary care is aimed at promoting, protecting, detecting, and modifying the changes that can have an impact on their future life. This occurs mainly through educational actions and comprehensive monitoring of a child's health [20]. The public manager is responsible for diagnosing health situations in his or her territory and surveying the health needs of the population so that their needs can be met through these services. Therefore, health is not just the absence of disease but also the promotion of measures that guarantee the well-being of the population [21]. The cross-sectional design of this research prevents an investigation of the cause-and-effect relationship between the independent variables and the early puberty outcome. New longitudinal studies may clarify this gap.

\section{Conclusion}

In conclusion, this research showed that $59.7 \%$ of the studied population was composed of brown-skinned children. The onset of the first symptoms of PP occurred at an average age of 6.4 years. The time elapsed between the appearance of secondary sexual characteristics and treatment initiation with gonadotropinreleasing hormone inhibitor was 1.1 years. The advancement of BA in children with PP compared to children without PP $(2.2$ years) can be attributed to the time elapsed between the onset of symptoms and the effectiveness of the treatment; this may also explain the difference in stature we observed when we compared girls with and without PP.

\section{References}

1. Bradley SH, Lawrence N, Steele C, Mohamed Z (2020) Precocious puberty. BMJ 368: 16597.
2. Maia NA (2014) Idiopathic central precocious puberty (ICPP) in girls: clinical and demographic aspects related to the racial group and treatment adherence. Monography (Medicine Graduation) Faculdade de Medicina, Universidade Federal da Bahia, Salvador.

3. Cabral ZAF (2014) Manual de ginecologia infanto juvenile São Paulo Federação Brasileira das Associações de Ginecologia e Obstetrícia.

4. Algo Mais (2018) The incidence of precocious puberty grows.

5. Greenspan L, Deardorff J (2014) The new puberty: How to navigate early development in today's girls. New York, NY: Rodale, USA.

6. Brazil Ministry of Health. National Commission for the Incorporation of Technologies in the SUS. Clinical protocol and therapeutic guidelines: central early puberty. Brasília.

7. (2016) Brazilian Institute of Geography and Statistics. Estimate: cities: Maranhão: São Luís.

8. Zilanawala A, Sacker A, Kelly Y (2016) Mixed ethnicity and behavioural problems in the Millennium Cohort Study. Archives of Disease in Childhood 103(1): 61-64.

9. Carvalho MN (2007) Precocious puberty: the experience of o Pediatric and Adolescent Gynecology Clinic. Rev Bras Ginecol Obstet 29 (2): 96102.

10. Cavalcante CJV, Correia LL, Damiani D (2014) Precocious puberty: associated conditions. Revista Brasileira Promoção Saúde 27(2): 153-162.

11. Aksglaede L, Sørensen K, Petersen JH, Skakkebaek NE, Juul A (2009) Recent decline in age at breast development: the Copenhagen Puberty Study. Pediatrics 123(5): e932-939.

12. Cruz ARV Approach to early puberty 2014. Dissertation (Integrated Master in Medicine) - Faculty of Medicine, University of Coimbra, Coimbra.

13. Xu YQ Li GM, Li Y (2018) Advanced bone age as an indicator facilitates the diagnosis of precocious puberty. J Pediatr (Rio J.) 94(1): 69-75.

14. Benetti Pinto CL (2008) Predictive factors for height gain in idiopathic central precocious puberty treated with GnRH analogue. Rev Bras Ginecol Obstet 30(12): 609-613.

15. (2017) Brazilian society of pediatrics. Health care: growth.

16. Castilho SD, Barras Filho AA (2000) Post menarche growth Arq Bras Endocrinol Metab 44(3): 195-204.

17. Alves C, Flores LC, Cerqueira TS, Toralles MBP (2007) Environmental exposure to endocrine disruptors with estrogenic activity and the association with pubertal disorders in children. Cad Saúde Pública 23(5): 1005-1014.

18. Girardon Perlini NMO, Ângelo M (2017) The experience of rural families in the face of cancer. Rev Bras Enferm 70(3): 550-557.

19. Santos EC, Ramos AS, Sousa EAS (2011) Pediatric care, the child's reaction humanized and parental satisfaction in the public service and private respiratory physiotherapy. Estação Científica 1(2): 69-84.

20. Barros FC, Victoria CG (2008) Maternal child health in Pelotas, Rio Grande do Sul State, Brazil: major conclusions from comparisons of the 1982, 1993, and 2004 birth cohorts. Cadernos de Saúde Pública 24(3): 461-467.

21. Pompeu JCBP Contractual situation of the private sector linked to SUS: some elements for reflection. 2004 Dissertation (master's in management of Health Systems and Services) Fundação Oswaldo Cruz. Sergio Arouca National School of Public Health, Rio de Janeiro. 
(C) Commons Attribution 4.0 License
Your next submission with Juniper Publishers will reach you the below assets

- Quality Editorial service

- Swift Peer Review

- Reprints availability

- E-prints Service

- Manuscript Podcast for convenient understanding

- Global attainment for your research

- Manuscript accessibility in different formats

( Pdf, E-pub, Full Tsext, Audio)

- Unceasing customer service

Track the below URL for one-step submission https://juniperpublishers.com/online-submission.php 